\title{
Prevalence, Psychological Responses and Associated Correlates of Depression, Anxiety and Stress in a Global Population, During the Coronavirus Disease (COVID-19) Pandemic
}

\author{
Syed Mustafa Ali Shah ${ }^{1} \cdot$ Danish Mohammad ${ }^{1} \cdot$ Muhammad Fazal Hussain Qureshi $^{1}$ (1) $\cdot$ Mohammad Zain Abbas $^{1}$. \\ Sameeha Aleem ${ }^{2}$
}

Received: 18 August 2020 / Accepted: 10 October 2020 / Published online: 27 October 2020

(c) Springer Science+Business Media, LLC, part of Springer Nature 2020

\begin{abstract}
Uncertainty and isolation have been linked to mental health problems. Uncertainty surrounding the COVID-19 pandemic has the potential to trigger mental health problems, which include anxiety, stress, and depression. This paper evaluates the prevalence, psychological responses, and associated correlates of depression, anxiety, and stress in a global population during the Coronavirus Disease (COVID-19) pandemic. A cross-sectional study design was adopted. 678 completed forms were collected during the COVID-19 quarantine/lockdown. An online questionnaire was designed and DASS-21 was used as the screening tool. A non-probability sampling technique strategy was applied. 50.9\% of participants showed traits of anxiety, $57.4 \%$ showed signs of stress, and 58.6\% exhibited depression. Stress, anxiety, and depression are overwhelmingly prevalent across the globe during this COVID-19 pandemic, and multiple factors can influence the rates of these mental health conditions. Our factorial analysis showed notable associations and manifestations of stress, anxiety, and depressive symptoms. People aged 18-24, females, and people in non-marital relationships experienced stress, anxiety, and depression. Separated individuals experienced stress and anxiety. Married people experienced anxiety. Single and divorced people experienced depression. Unemployed individuals experienced stress and depression. Students experienced anxiety and depression. Canada, the UK, and Pakistan are all countries that are experiencing stress and depression as a whole. An extended number of days in quarantine was associated with increased stress, anxiety, and depression. Family presence yielded lower levels of stress, anxiety, and depression. Lastly, lack of exercise was associated with increased stress, anxiety, and depression.
\end{abstract}

Keywords Stress $\cdot$ Anxiety $\cdot$ Depression $\cdot$ COVID $19 \cdot$ Corona $\cdot$ Quarantine

\section{Introduction}

On the 30th of January, 2020, the World Health Organization (WHO) declared the outbreak of COVID-19 a public health emergency of international concern (Gallegos 2020). On March 11, they declared it a global pandemic, their first such decision since they declared H1N1 influenza a pandemic back in 2009 (Times 2020). As of 24th May, 2020, there were over 5.2 million confirmed cases of COVID-19,

Muhammad Fazal Hussain Qureshi

fazalhqureshi22@gmail.com

1 Ziauddin University, 4/B, Shahrah-e-Ghalib, Block 6, Clifton, Karachi, Pakistan

2 Department of Psychiatry (MBBS, FCPS), Ziauddin Medical Hospital, KDLB Campus, Karachi, Pakistan and over 330,000 confirmed deaths worldwide (Organization 2020). As a response to this global health crisis, strict public health measures have been implemented to prevent the spread of this virus, including avoidance of public contact and quarantines (Adhikari et al. 2020). According to the CDC, quarantine refers to the separation of humans or animals in order to prevent the spread of disease (Prevention 2017).

The uncertainty surrounding this pandemic could potentially trigger mental health problems, such as anxiety and depression, in certain subsets of the population (Dar et al. 2017). Social isolation, in general, has been linked to both physical, and mental health problems (Holt-Lunstad et al. 2015). A review of psychological sequelae in samples of quarantined people found that reports of negative psychological effects were common (Brooks et al. 2020). These included confusion, anger, and symptoms of post-traumatic 
stress. The review shed light on potential stressors, which included factors like a longer quarantine duration, fear of infection, frustration, boredom, inadequate supplies, inadequate information, financial loss, and stigma. A 2004 study conducted after the containment of the SARS outbreak showed similar negative psychological effects associated with quarantine. They found that $28.9 \%$ of respondents had symptoms of PTSD and $31.2 \%$ had symptoms of depression (Hawryluck et al. 2004). Longer durations of quarantine were associated with an increased prevalence of PTSD symptoms, and acquaintance with, or direct exposure to, someone with a diagnosis of SARS was also associated with PTSD and depressive symptoms.

Considering that there were 8439 confirmed cases and 812 deaths during the SARS outbreak, it is safe to say that the current pandemic is on a whole different scale in terms of its impact on the global population (Martin 2020). This, combined with the fact that literature exploring the mental health effects of the pandemic is scanty in comparison with the vast bodies of work looking into its physical effects, is what led us to initiate this research. The tool we chose o employ was the Depression Anxiety Stress Scale-21 (DASS21), which has been found to be a valid and reliable instrument for measuring depression, anxiety and stress (Dreyer et al. 2019).

According to the American Psychiatric Association, depression is defined as feelings of sadness and/or a loss of interest in activities once enjoyed which can lead to a variety of emotional and physical problems and can decrease a person's ability to function at work or at home, with symptoms lasting at least two weeks required for a diagnosis (Association, January 2017a). They describe anxiety disorders as excessive fear or anxiety and mention that these are the most common of all mental disorders (Association, January 2017b). Stress can be defined as a physical, mental or emotional factor that causes bodily or mental tension (Shiel 2018).

There is a need for mental health studies to be conducted in order to understand the full extent of the psychological impacts of a pandemic of this magnitude. This paper aims to evaluate the effects of self-isolation and quarantine on mental health, and add to the growing body of literature available on this topic.

\section{Methodology}

\section{Study Design and Participants}

A cross-sectional study design was adopted to evaluate mental health using DASS-21 during self-quarantine/isolation amidst the COVID-19 pandemic. A total of 749 questionnaires were collected from which 678 were completed and valid for analysis, which is a response rate of $90.5 \%$ (95\% confidence interval with a $5 \%$ margin of error). Female respondents comprised $57.2 \%(\mathrm{n}=388)$ of the sample, while $42.8 \%$ were male $(n=290)$. Ages groups were divided into: $<18,18-24,25-34,35-44,45-54$ and 54+. Ages 18-24 and 25-34 noted higher response rates relative to the other age groups. Average completion time for the questionnaire was 5 mins. The analysis excluded surveys from people aged less than 14 (Lovibond 2014), or those with missing answers in the DASS-21 section.

\section{Procedure}

An online questionnaire was designed, and then disseminated using a non-probability sampling strategy. Social media platforms were utilized to distribute survey links. Each link included a brief text, detailing the nature of the study, for people to read before participation. Confidentiality and anonymity were ensured. This study was performed in line with the principles of the Declaration of Helsinki and was approved by the institutional review board of the authors' parent university.

\section{Measures}

The questionnaire predominantly consisted of two sections of a multiple-choice format. The first section covered basic demographic data (age, gender, marital/relationship status, country of residence), potential stressors (length of time in self-quarantine/isolation, living arrangements, specific employment/study status), and coping mechanisms (exercise frequency, number of outings, interaction and impact of friends, family and pets). The second section consisted of the Depression Anxiety and Stress Scale, which is a 21-item shortened version of the Depression Anxiety Stress Scales-42. This scale is in the public domain and tests three related negative emotional states (depression, anxiety, and stress). The depression scale evaluates dysphoria, hopelessness, absence of interest/involvement, devaluation of life, self-deprecation, anhedonia and inertia. The anxiety scale judges autonomic arousal, situational anxiety, skeletal muscle effects and experiences of anxiousness. The stress scale is receptive to persistent, non-specific arousal. It evaluates difficulty unwinding, nervous arousal, and mood changes (distress, agitation, irritability, over-reactiveness and impatience) (Lovibond 2014) Experiences such as "I tended to over-react to situations" (stress), "I felt scared without any good reason" (anxiety), and "I felt that I had nothing to look forward to" (depression) were recorded by rating on a 4-point Likert scale, ranging from 1 (did not apply to me at all) to 3 (applied to me very much, or most of the time). Total scores for depression, anxiety and stress were calculated by aggregating their corresponding points. Each 
total was then doubled and then classified "normal", "mild", "moderate", "severe" or "extremely severe". Levels of sensitivity and specificity of 78-89\% and 71-76\% were found for the DASS-21. (Beaufort et al. 2017) Validity of the questionnaire was checked using Cronbach's alpha, and its value was 0.808 .

\section{Statistical Analysis}

Data was entered into IBM SPSS version 20.0 (Armonk, NY, USA) and Statistical Analysis System (SAS). The Kaiser-Meyer-Olkin (KMO) measure of sampling adequacy \& Bartlett's test of sphericity were satisfied (KMO $>0.50$ and Bartlett's test $<0.05$ ). Once this prerequisite was met, multifactorial analysis was performed. A confirmatory bifactor model was used and organized into a general factor (communalities) and three domain-specific factors (stress, anxiety and depression). These factors were evaluated against each specific DASS-21 question. Communalities demonstrated the overall strength of the factor while factor 1, 2 and 3 (stress, anxiety, and depression respectively) described the particular domain where that strength was most prominent. The variance of each item is distributed between the communalities, stress, anxiety, depression factors (Shaw et al. 2017). Values greater than 0.300 are significant. Furthermore, higher values indicate greater strength.

The Chi-square test was applied on the skewed categorical data while the remaining analysis was done via ANOVA and Tukey's Honest Significant Difference test. The tests were two-tailed, and the significance level chosen was a p-value $<0.05$. Descriptive frequencies were also applied to assess some sociodemographic variables and highlight notable trends.

\section{Results}

A total of 749 forms were collected. 678 were complete and were used for analysis. The response rate was $90.5 \%$. The largest number of respondents were from the USA $(n=210)$, followed by Pakistan, Canada and the UK respectively. The USA on average showed fewer symptoms of depression and stress relative to Canada and Pakistan. 'Others' includes samples from the Middle East (Oman, Lebanon, UAE, Qatar, Saudi Arabia), Europe (Switzerland, Hungary, Finland, Germany, Ireland, Turkey, Norway, Romania, Spain, Netherlands, Greece), Sri Lanka, Malaysia, Costa Rica, Trinidad and Australia (Fig. 1).

Amongst this, $24.5 \%$ of participants had moderate anxiety, $10.2 \%$ suffered from extremely severe anxiety, $9.3 \%$ had mild anxiety, and $6.9 \%$ had severe anxiety. $49.1 \%$ had no characteristics of anxiety and were considered normal, as shown in Fig. 2a.

\section{Country}

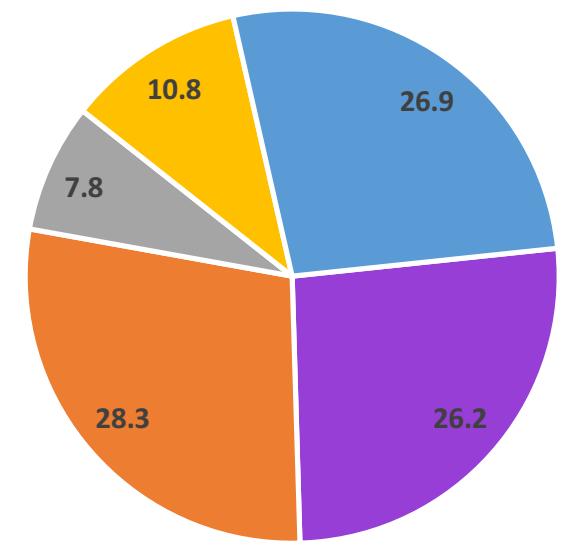

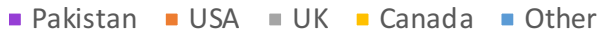

Fig. 1 Country wise representation of participants in percentage

$57.4 \%$ had signs of stress, including $32.2 \%$ experiencing mild stress, $17 \%$, moderate stress, $6.6 \%$, severe stress, and $1.6 \%$ enduring extremely severe stress. $42.6 \%$ had no signs of stress and were considered normal, as shown in Fig. $2 \mathrm{~b}$. $58.6 \%$ of participants showed indications of depression, with $20.1 \%$ experiencing moderate depression, $16.1 \%$, mild depression, $11.7 \%$, extremely severe depression, and $10.8 \%$, severe depression. $41.4 \%$ were normal and had no features of depression, as represented in Fig. 2c.

\section{DASS 21 Scores and Age}

Chi-Square determined the association between age and DASS 21 scores. Significant p-values of 0.027, 0.002, and $<0.001$ were reached for stress, anxiety, and depression respectively. Frequency distribution showed that the age group of 18-24 experienced more stress, anxiety, and depression compared to the other age groups of $<18$, $25-34,35-44,45-54$ and $54+$.

\section{DASS 21 Scores and Gender}

Chi-Square determined the association between genders and DASS 21 scores. Highly significant p-values of $<0.001$ were obtained for stress, anxiety and depression. Frequency distribution revealed that females experienced more stress, anxiety, and depression than their male counterparts. 
(a) Anxiety

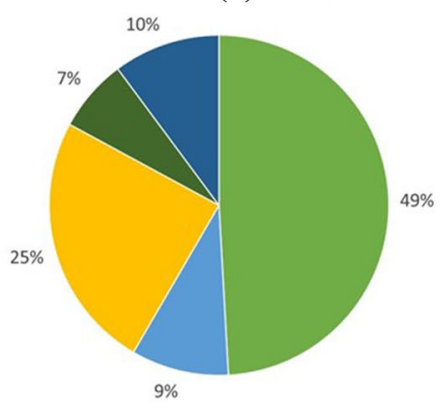

(b) Stress

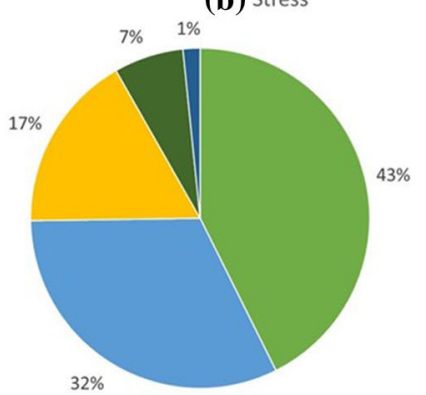

Normal

= Mild

= Moderate

- Severe

- Extremly Severe

(c) Depression

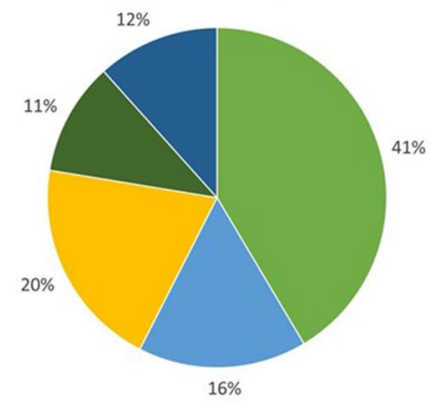

Fig. 2 Overall anxiety, stress and depression scores

\section{Multifactorial Analysis of DACC 21}

The data demonstrated a normal distribution and all prerequisites were met before applying the model. Parallel analysis gave the three factors, stress, anxiety, and depression, an eigenvalue of greater than 1 . Factorial analysis was then performed and is illustrated in Table 1. Factor 1 (stress) generated $42.3 \%$ variance, factor 2 (anxiety), $4.76 \%$, and factor 3 (depression), $2.25 \%$. Communalities show the strength of the factor in general while factor 1, 2 and 3 show the specific domain where that strength is most influential. A value above 0.3 is considered significant. Moreover, the greater the value, the greater the influence.

A few factors in the anxiety domain show more association with stress instead of anxiety, as shown in Table 1.

\section{DASS 21 Scores and Relationship Status}

ANOVA determined the significance between Relationship Status and DASS 21 scores. Tukey's Honest Significant Difference test investigated specific associations:

(1) Stress: ANOVA produced a significant P-value of 0.008 . The Post-hoc Tukey test found significantly higher stress scores amongst people who are separated or in a non-marital relationship, and found no significant associations amongst the single, married, or widowed categories.
(2) Anxiety: ANOVA produced a highly significant P-value of $<0.001$. The Post-hoc Tukey test found significantly higher anxiety scores amongst people who are married, separated, or in a non-marital relationship, and found no significant associations amongst the single, divorced or widowed categories.

(3) Depression: ANOVA produced a highly significant P-value of $<0.001$. The Post-hoc Tukey test found significantly higher depression scores amongst people who are single, divorced or in a non-marital relationship, and no significant association amongst the married and widowed categories.

\section{DASS 21 Scores and Occupation}

ANOVA determined the significance between Occupation Status and DASS 21 scores. Tukey's Honest Significant Difference test investigated specific associations:

(1) Stress: ANOVA generated a highly significant P-value of $<0.001$. The Post-hoc Tukey test found significantly higher stress scores amongst the unemployed, non-essential workers that could not work during the pandemic, and students. Essential workers and nonessential workers able to work from home didn't show significant association with stress levels.

(2) Anxiety: ANOVA generated a significant P-value of 0.006. The Post-hoc Tukey test identified significantly higher anxiety scores amongst the students. Essential 
Table 1 Multifactorial analysis of DACC 21

\begin{tabular}{|c|c|c|c|c|c|}
\hline & Question & Communalities & $\begin{array}{l}\text { Factor } 1 \\
\text { (Stress) }\end{array}$ & $\begin{array}{l}\text { Factor } 2 \\
\text { (Anxiety) }\end{array}$ & $\begin{array}{l}\text { Factor } 3 \\
\text { (Depression) }\end{array}$ \\
\hline \multirow[t]{7}{*}{ Stress } & I found it hard to wind down & 0.347 & 0.433 & 0.033 & 0.147 \\
\hline & I felt that I was rather touchy & 0.344 & 0.403 & 0.018 & 0.187 \\
\hline & $\begin{array}{l}\text { I was intolerant of anything that kept me from getting on with what I was } \\
\text { doing }\end{array}$ & 0.406 & 0.602 & 0.002 & 0.039 \\
\hline & I tended to over-react to situations & 0.522 & 0.581 & 0.132 & 0.259 \\
\hline & I found myself getting agitated & 0.565 & 0.820 & 0.057 & 0.026 \\
\hline & I found it difficult to relax & 0.594 & 0.658 & 0.234 & 0.048 \\
\hline & I felt that I was using a lot of nervous energy & 0.546 & 0.424 & 0.003 & 0.394 \\
\hline \multirow[t]{7}{*}{ Anxiety } & I was aware of the action of my heart in the absence of physical exertion & 0.654 & 0.127 & 0.737 & 0.161 \\
\hline & I experienced breathing difficulty (e.g., excessive rapid breathing) & 0.654 & 0.164 & 0.619 & 0.249 \\
\hline & I felt scared without any good reason & 0.614 & 0.622 & 0.317 & 0.060 \\
\hline & I was aware of dryness of my mouth & 0.609 & 0.616 & 0.340 & 0.092 \\
\hline & I felt I was close to panic & 0.460 & 0.384 & 0.310 & 0.089 \\
\hline & $\begin{array}{l}\text { I was worried about situations in which I might panic and make a fool of } \\
\text { myself }\end{array}$ & 0.639 & 0.694 & 0.234 & 0.048 \\
\hline & I experienced trembling (e.g., in the hands) & 0.462 & 0.658 & 0.074 & 0.055 \\
\hline \multirow[t]{9}{*}{ Depression } & I felt life was meaningless & 0.334 & 0.097 & 0.074 & 0.617 \\
\hline & I felt I wasn't worth much as a person & 0.370 & 0.037 & 0.006 & 0.578 \\
\hline & I was unable to become enthusiastic about anything & 0.542 & 0.196 & 0.146 & 0.527 \\
\hline & I felt that I had nothing to look forward to & 0.118 & 0.077 & 0.068 & 0.265 \\
\hline & I couldn't seem to experience any positive feeling at all & 0.579 & 0.314 & 0.078 & 0.484 \\
\hline & I felt down-hearted and "blue" or sad & 0.467 & 0.306 & 0.026 & 0.412 \\
\hline & I found it difficult to work up the initiative to do things & 0.378 & 0.005 & 0.104 & 0.597 \\
\hline & Percentage of variance & & 42.3 & 4.76 & 2.25 \\
\hline & Eigenvalue & & 9.43 & 1.47 & 1.12 \\
\hline
\end{tabular}

Bold values indicate the significant figures for the specific test used

workers, non-essential workers (both with continued work and those with halted work), as well as those who were unemployed, didn't show significant association with anxiety level.

(3) Depression: ANOVA generated a highly significant P-value of $<0.001$. The Post-hoc Tukey test noted significantly higher depression scores amongst students and those who were unemployed. Essential workers and non-essential workers (both with continued work and those with halted work) didn't show significant association with depression level.

\section{DASS 21 Scores and Countries}

ANOVA assessed relationships between Country of Residence and DASS scores. Tukey's Honest Significant Difference test was used to further investigate specific associations:

1. Stress: ANOVA identified a significant P-value of 0.002 . The Post-hoc Tukey test discovered significantly higher stress scores amongst individuals in Canada, followed by the UK, and then Pakistan. Individuals in the USA, India, and Middle Eastern and European countries (excluding the UK) didn't exhibit significant associations with stress levels.

2. Anxiety: ANOVA found a non-significant p-value of 0.100. Consequently, the Post-hoc Tukey was not performed.

3. Depression: ANOVA identified a significant P-value of 0.002. The Post-hoc Tukey test demonstrated significantly higher stress scores amongst individuals living in Canada, followed by the UK, and then Pakistan. Individuals in the USA, India, and Middle Eastern and European countries (excluding the UK) didn't exhibit significant associations with depression levels.

\section{Linear Regression Analysis of DASS Scores}

The linear regression model was applied to ascertain the relationship of DASS 21 scores with the number of days quarantined, as well as with the impact of family, friends and pets: 
1. Notably, an extended number of days in quarantine was associated with a significant increase in stress scores (p-value of 0.011).

2. People who resided with family showed significantly lower stress scores, a p-value of $<0.001$, indicating that the presence of family may serve as a source of relief. The same pattern was observed in the domains of anxiety and depression as well.

\section{DASS 21 Scores and Pets}

Chi-Square found no significant p-values for pets and DASS 21 scores: Stress (0.174), Anxiety (0.513) and Depression (0.919).

\section{DASS 21 Scores and Exercise}

ANOVA evaluated the relationship of exercise on DASS scores. Tukey's Honest Significant Difference test was used to further investigate specific associations:

1. Stress: ANOVA found a significant P-value of 0.005 . The Post-hoc Tukey test described significantly higher stress scores amongst those who did not exercise at all during the pandemic. No such association was found amongst those who work out.

2. Anxiety: ANOVA found a significant P-value of 0.003 . The Post-hoc Tukey test found significantly higher anxiety scores amongst people who did not exercise at all during the pandemic. No such association found amongst those who work out.

3. Depression: ANOVA found a highly significant P-value of $<0.001$. The Post-hoc Tukey test found significantly higher depression scores amongst people who did not exercise at all during the pandemic. No such association found amongst those who work out.

\section{Discussion}

Anxiety, stress, and depression are prevalent worldwide during the quarantine/social isolation caused by the COVID 19 pandemic. This research was conducted between April 27th and 13th May, 2020. Our goal was to narrow down possible correlates of depression, anxiety, and stress, as well as note potential causes and coping mechanisms.

Anxiety, stress and depression levels were high in our study compared to other set ups for specific countries. A study from China, using the DASS 21 questionnaire on a sample of 1210 Chinese participants, revealed that $28.8 \%$ suffered from anxiety, 53.8\% suffered from stress, and $16.1 \%$ suffered from depression (Cuiyan Wang et al. 2020a, b). In comparison, our results show a stark increase in these numbers, which emphasizes the importance of this problem. The aforementioned Chinese study analyzed the effects of COVID during the initial stages of the outbreak, which lasted two weeks. In contrast, our study assessed the significance of varying durations of lockdown and its effect on mental health, and noted a higher level of anxiety prevalent longer into the outbreak. Another study of 343 Turkish people during COVID-19 found $45.1 \%$ of participants to be experiencing anxiety, and depression rates of $23.6 \%$ in its population (Özdin and Bayrak Özdin). The results from our study show higher rates of anxiety and depression, again indicating that there is a growing problem. Looking deeper, the reason for growing anxiety may be health anxiety (Asmundson and Taylor 2020), which is when observed bodily sensations (connected to infectious disease or not) are perceived as an illness, but may not necessarily be the actual disease (Asmundson et al. 2010). Peteet states possible reasons for anxiety, including uncertainty, fear of infection, moral distress, and grief, especially when alone (Cullen et al. 2020). Unprecedented exposure to news/media, while keeping us informed, may also result in misinformation (Asmundson et al. 2010), enhancing the negative impact on mental health. In terms of stress, no specific reasons are found. Additionally, 14 studies looking at COVID healthcare workers found an increase in stress manifestations amongst 2.2-14.5\% of participants (Bohlken et al. 2020). This reaffirms the degree of stress that is present during the COVID outbreak. Rates of depression in Spain became higher from March 14th, which is when the lockdown began (OzamizEtxebarria and Dosil-Santamaria 2020). A meta-analysis of 10 studies about healthcare workers during the COVID outbreak revealed a depression rate of $22.8 \%$ (Pappa et al. 2020). To summarise, our study shows a higher prevalence of anxiety, stress, and depression in our depicted worldwide sample.

Our study used multifactorial analysis to identify the associations of stress, anxiety, and depression with how they manifest, as shown in Table 1. Examining individual factors is essential, but different populations may show different symptoms. For example, one study that analyzed college students' factorial suggests that DASS 21 on clinical patients may report different corresponding characteristics (Osman et al. 2012). Consequently, we tried to mitigate population differences by analyzing factorial traits on a general population worldwide, to identify common manifestations during the pandemic and quarantine. Main complaints in our sample seemed to be, "I found myself getting agitated," followed by "I found it difficult to relax." These symptoms are in contrast with a past study done in Asia, which noted traits like, "I felt rather touchy," to be more significant (Oei et al. 2013) (Table 2).

In the anxiety scale, traits such as "I was aware of the action of my heart in the absence of physical exertion" and 
Table 2 Linear Regression analysis of DASS scores with the number of days quarantined and impact of family, friends, and pets during quarantine

\begin{tabular}{lcll}
\hline & \multicolumn{2}{l}{ Model 01 } & \\
\cline { 2 - 3 } & $\mathrm{B}$ & $\mathrm{SE}$ & $\mathrm{p}$-value \\
\hline Stress & & & \\
Number of days quarantined & 0.296 & 0.116 & $0.011^{*}$ \\
Number of outings & -0.21 & 0.76 & 0.786 \\
Impact of family & -1.503 & 0.172 & $0.000^{*}$ \\
Impact of friends & -0.243 & 0.156 & 0.120 \\
Impact of pets & 0.195 & 0.169 & 0.249 \\
Anxiety & & & \\
Number of days quarantined & 0.273 & 0.084 & $0.001^{*}$ \\
Number of outings & -0.006 & 0.055 & 0.911 \\
Impact of family & -0.999 & 0.126 & $0.000^{*}$ \\
Impact of friends & -0.120 & 0.113 & 0.292 \\
Impact of pets & 0.138 & 0.123 & 0.263 \\
Depression & & & \\
Number of days quarantined & 0.287 & 0.082 & $0.001^{*}$ \\
Number of outings & -0.67 & 0.054 & 0.218 \\
Impact of family & -1.343 & 0.119 & $0.000^{*}$ \\
Impact of friends & -0.192 & 0.111 & 0.085 \\
Impact of pets & -0.53 & 0.120 & 0.661 \\
\hline
\end{tabular}

Significant values have been marked by an asterisk (*)

"experienced breathing difficulty" were rated highly significant. This is similar to the aforementioned Asian population. Therefore, we can infer these traits of anxiety are likely experienced worldwide (Oei et al. 2013).

Lastly, when depression was analyzed, "I felt life was meaningless" and "I found it difficult to work up the initiative to do things" were the main associations observed. The prior study noted "I found it difficult to work up the initiative to do things," as having a lower association to depression, whereas "I felt life was meaningless" had a similar significance as in our study (Oei et al. 2013).

Age is a risk factor for overall levels of stress, anxiety, and depression, all three of which were significantly increased in the range of 18-24. This is similar to depression levels observed in northern Spain, which show higher stress, anxiety, and depression in the range of 18-26 (Ozamiz-Etxebarria and Dosil-Santamaria 2020). A study in China states that anxiety and depression were more prevalent in students during the initial outbreak (Cuiyan Wang et al. 2020a, b). This could be because students are having to adapt quickly, going from a face to face environment to an online one (Antúnez and Vinet 2012; Martín Monzón 2007; Naiara Ozamiz-Etxebarria et al. 2020). Past studies involving college students, from Jordan and Ohio, suggested that high levels of stress, anxiety, and depression can be due to pressure to succeed and postgraduate career plans (Beiter et al. 2015). The study from Ohio also used DASS-21, affirming that our results are comparable to other papers. Through these studies, we can infer that uncertainty regarding the changing socio-economic environment in a post-COVID-19 world is a likely source of crippling mental health.

Females experience more stress, anxiety, and depression overall. Similar findings are seen in China, Turkey, Italy, and Spain (Özdin and Bayrak Özdin 2020a, b; Cuiyan Wang et al. 2020a, b). Studies from Italy and Spain used the same DASS-21 questionnaires, showing similarities, and consistency with our data. Literature suggests that women experience a high prevalence of mood and anxiety disorders (Lim and Tam 2018; Onrust and Cuijpers 2006). Moreover, they have greater chances of developing stress and PTSD during the pandemic (Liu et al. 2020; Sareen et al. 2013).

Relationship status can contribute to stress, anxiety and depression. Married people have greater anxiety during quarantine. This can stem from dissatisfaction or the perception of a support imbalance (Kasalova et al. 2018). The lockdown may require a greater degree of support from partners, which may not always be provided. There is limited literature on anxiety in non-marital relationships and separated couples. However, some pre-existing studies state that non-marital monogamous relationships can involve more jealousy, and more time spent rationalizing thoughts of jealousy (Balzarini et al. 2019; Mogilski et al. 2019).

Depression is seen in single individuals and divorced couples. These people may feel a sense of loneliness which correlates to increased rates of depression (Matthews et al. 2016; Wang et al. 2017).

Occupation status can contribute to stress, anxiety, and depression. Increased stress was observed in the unemployed, and in non-essentials workers (specifically those with work on halt). Increased levels of anxiety were seen in students. Raised levels of depression were seen in students and the unemployed.

There's a relationship between stress, and the unemployed $\&$ non-essential workers (specifically those unable to work), indicating that both lack of work, and uncertainty in relation to work, may cause raised stress. The international labor organization, on March 18th, 2020, stated that 5.3 million to 24.7 million people are projected to lose their jobs in the COVID pandemic (Organization). In such a scenario, the numbers for stress are likely to increase drastically. However, an absolute causal relationship could not be established. In a sample of 224 participants, $10.4 \%$ had high stress amidst unemployment (Mæhlisen et al. 2018). The unemployed being significantly stressed may suggest a causal relationship, but causality can not be established until additional investigations are performed.

Elevated anxiety was seen in the student population. A study from China reported $24.9 \%$ of college students suffering from anxiety (Cao et al. 2020) during COVID-19 due 
to concerns about the virus' effects on studies and future employment (Cornine 2020; Wang et al. 2020a, b). In our study, we see a trend where Canadian students and students residing in the UK seem to be at higher risk for depression. Notably, these countries have some of the highest-ranked universities in the world. Political and economic stability play an important role in students' decisions regarding their school (Pietrucha 2018). Thus, it is reasonable to assume that the growing political and economic uncertainty postCOVID-19, particularly in countries renowned for education, is a pressing concern for students. Also, to note, our sample of ages ranging from 18-24 had higher anxiety levels. This age span corresponds to students and those at the initial stages of exploring career prospects. Moreover, economic stressors and delays in daily student activities were a significant factor in anxiety (Cao et al. 2020).

Our investigation found raised levels of depression in students, as well as the unemployed population. In 2000-2011 (including the 2008 economic crisis), suicide rates had elevated 20-30\% (Kawohl and Nordt 2020) during mass unemployment. In a sample of 364 unemployed participants, 188 were considered clinically depressed (Nurmela and Mattila 2018). The effects of unemployment on mental health, particularly depression, are clear to see. It is also seen that quarantined health care workers show higher cases of depression than others in the population (Chatterjee and Chauhan 2020; Xiang et al. 2020), thereby highlighting a need for additional research regarding work and mental health (Kumari et al. 2019). Additional investigations are required to understand the extent of mental health disorder resulting from changes to occupation status, workload, changes in education (particularly to online format), increasing student courses (and assessment curriculum), and uncertain post-COVID-19 socioeconomics, particularly in the younger age group (18-24). Nonetheless, there is a high correlation with depression amongst students and the unemployed.

When observing individual countries, the highest scores of stress and depression were found in Canada, the United Kingdom, and then Pakistan respectively. It is surprising to see this result considering Canada has fewer cases than the UK. However, according to WHO, as of May 28th, we find that the number of cases in the Americas is the highest in the world (Organization 2020) (notably due to the USA). Thus, health anxiety amongst rapidly growing coronavirus cases seems to be a logical reason for mental health disorders. It can not be fully explained why Pakistan has high scores despite a lower number of cases than other countries. One theory is that Pakistani culture relies heavily on family and community involvement, hence social isolation may produce more marked mental health effects. Nonetheless, Canada, the UK, and Pakistan conclusively showed significant values for stress and depression. Further research is warranted to identify the reasons.
Literature regarding family impact during the COVID outbreak is sparse. Our study found that increased family presence was associated with decreased levels of stress, anxiety, and depression. Social isolation has a higher effect on loneliness (Leigh-Hunt et al. 2017), and we also know that the elderly are highly susceptible to depression and many mental health problems in social isolation. (Armitage and Nellums 2020; Leigh-Hunt et al. 2017) Consequently, there is a dire need to focus on balanced social distancing, allowing intermittent meetings with family and friends while honoring appropriate safety measures to mitigate some of the adverse mental health impacts of COVID-19.

Our research sets up adequate groundwork for the current COVID-19 mental health profile. Additional studies must be conducted to notice developing trends and factors in response to COVID-19. The more literature that can be developed globally, the better-equipped governments and organizations will be to provide adequate long term management and support (Klomek 2020). This research gives insight on factors which predispose individuals to anxiety, stress and depression during COVID-19 (including, but not limited to, students, females, unemployed, divorced). More research is warranted to look into these groups and establish absolute causes.

There are limitations to every study, including ours. Despite having a sample size of 678 , with a confidence interval of $95 \%$ and a $5 \%$ margin of error, a larger sample and more resources are needed to get a true representation of the world population. Some countries may be missed in this study which would have been prevented with a larger sample size. Furthermore, the rapidly evolving COVID-19 situation around the world indicates that current information and results are likely to change.

\section{Conclusion}

Our study shows that anxiety, stress, and depression are overwhelmingly prevalent in the world during COVID 19. Surveys were collected on April 27th-13th May, 2020. Our factorial analysis showed notable associations and manifestations of stress, anxiety, and depression symptoms. People aged 18-24, females, and non-marital relationships experienced stress, anxiety, and depression. Separated individuals experienced stress and anxiety. Married people experienced anxiety. Single and divorced people experienced depression. Unemployed individuals experienced stress and depression. Students experienced anxiety and depression. Non-essential workers that aren't currently working experience stress. Canada, UK, and Pakistan are countries that are experiencing stress and depression as a whole. Extended days in quarantine were associated with increased stress, anxiety, and depression. Family presence yielded decreased stress, 
anxiety, and depression. Lastly, lack of exercise was associated with increased stress, anxiety, and depression.

Funding This research did not receive any specific grant from funding agencies in the public, commercial, or not-for-profit sectors.

\section{Compliance with Ethical Standards}

Conflict of interest There are no conflict of Interest among authors.

Ethical Approval This study was performed in line with the principles of the Declaration of Helsinki and was approved by institutional review board of Parent University of authors.

Informed Consent Informed written consent was obtained from all individual participants included in the study.

\section{References}

Adhikari, S. P., Meng, S., Wu, Y. J., Mao, Y. P., Ye, R. X., Wang, Q. Z., et al. (2020). Epidemiology, causes, clinical manifestation and diagnosis, prevention and control of coronavirus disease (COVID19) during the early outbreak period: a scoping review. Infect Dis Poverty, 9(1), 29.

Antúnez, Z., \& Vinet, E. V. (2012). Escalas de Depresión, Ansiedad y Estrés (DASS- 21): Validación de la versión abreviada en estudiantes universitarios Chilenos. [Depression Anxiety Stress Scales (DASS-21): Validation of the abbreviated version in Chilean university students.]. Terapia Psicológica, 30(3), 49-55.

Armitage, R., \& Nellums, L. B. (2020). COVID-19 and the consequences of isolating the elderly. The Lancet Public Health, 5(5), e256.

Asmundson, G. J. G., Abramowitz, J. S., Richter, A. A., \& Whedon, M. (2010). Health anxiety: Current perspectives and future directions. Current Psychiatry Reports, 12(4), 306-312.

Asmundson, G. J. G., \& Taylor, S. (2020). How health anxiety influences responses to viral outbreaks like COVID-19: What all decision-makers, health authorities, and health care professionals need to know. Journal of Anxiety Disorders, 71, 102211.

Association., A. P. (January 2017a). What are Anxiety Disorders? American Psychiatric Association. . 2020, from https://www. psychiatry.org/patients-families/anxiety-disorders/what-are-anxie ty-disorders.

Association., A. P. (January 2017b). What are Anxiety Disorders?. American Psychiatric Association., 2020, from https://www.psych iatry.org/patients-families/anxiety-disorders/what-are-anxietydisorders.

Balzarini, R. N., Dharma, C., Kohut, T., Campbell, L., Lehmiller, J. J., Harman, J. J., et al. (2019). Comparing relationship quality across different types of romantic partners in polyamorous and monogamous relationships. Archives of Sexual Behavior, 48(6), $1749-1767$.

Beaufort, I. N., De Weert-Van Oene, G. H., Buwalda, V. A. J., de Leeuw, J. R. J., \& Goudriaan, A. E. (2017). The Depression, Anxiety and Stress Scale (DASS-21) as a screener for depression in substance use disorder inpatients: A pilot study. European Addiction Research, 23(5), 260-268.

Beiter, R., Nash, R., McCrady, M., Rhoades, D., Linscomb, M., Clarahan, M., et al. (2015). The prevalence and correlates of depression, anxiety, and stress in a sample of college students. Journal of Affective Disorders, 173, 90-96.
Bohlken, J., Schömig, F., Lemke, M. R., Pumberger, M., \& RiedelHeller, S. G. (2020). COVID-19 pandemic: Stress experience of healthcare workers: A short current review. Psychiatrische Praxis, 47(4), 190-197.

Brooks, S. K., Webster, R. K., Smith, L. E., Woodland, L., Wessely, S., Greenberg, N., et al. (2020). The psychological impact of quarantine and how to reduce it: Rapid review of the evidence. The Lancet, 395(10227), 912-920.

Cao, W., Fang, Z., Hou, G., Han, M., Xu, X., Dong, J., et al. (2020). The psychological impact of the COVID-19 epidemic on college students in China. Psychiatry Research, 287, 112934-112934.

Chatterjee, K., \& Chauhan, V. S. (2020). Epidemics, quarantine and mental health. Medical Journal Armed Forces India, 76(2), $125-127$.

Cornine, A. (2020). Reducing nursing student anxiety in the clinical setting: An integrative review. Nurs Educ Perspect.

Cullen, W., Gulati, G., \& Kelly, B. D. (2020). Mental health in the COVID-19 pandemic. QJM: Monthly Journal of the Association of Physicians, 113(5), 311-312.

Dar, K. A., Iqbal, N., \& Mushtaq, A. (2017). Intolerance of uncertainty, depression, and anxiety: Examining the indirect and moderating effects of worry. Asian Journal of Psychiatry, 29, 129-133.

Dreyer, Z., Henn, C., \& Hill, C. (2019). Validation of the Depression Anxiety Stress Scale-21 (DASS-21) in a non-clinical sample of South African working adults. Journal of Psychology in Africa, 29(4), 346-353.

Gallegos, A. (2020, January 30). WHO declares public health emergency for Novel Coronavirus. Medscape Medical News. Retrieved from https://www.medscape.com/viewarticle/924596.

Hawryluck, L., Gold, W. L., Robinson, S., Pogorski, S., Galea, S., \& Styra, R. (2004). SARS control and psychological effects of quarantine, Toronto, Canada. Emergency Infectious Disease, 10(7), 1206-1212.

Holt-Lunstad, J., Smith, T. B., Baker, M., Harris, T., \& Stephenson, D. (2015). Loneliness and social isolation as risk factors for mortality: A meta-analytic review. Perspect Psychological Science, 10(2), 227-237.

Kasalova, P., Prasko, J., Holubova, M., Vrbova, K., Zmeskalova, D., Slepecky, M., et al. (2018). Anxiety disorders and marital satisfaction. Neuro Endocrinological Letters, 38(8), 555-564.

Kawohl, W., \& Nordt, C. (2020). COVID-19, unemployment, and suicide. The Lancet Psychiatry, 7(5), 389-390.

Klomek, A. B. (2020). Suicide prevention during the COVID-19 outbreak. The Lancet Psychiatry, 7(5), 390.

Kumari, U., Dawani, N., Devnani, J., Qureshi, M. F. H., Soleja, F. K., Mohammad, D., ... Sadiq, S. (2019). Depression among medical students of Karachi a cross sectional study. MedEdPublish, 8 .

Leigh-Hunt, N., Bagguley, D., Bash, K., Turner, V., Turnbull, S., Valtorta, N., et al. (2017). An overview of systematic reviews on the public health consequences of social isolation and loneliness. Public Health, 152, 157-171.

Liu, N., Zhang, F., Wei, C., Jia, Y., Shang, Z., Sun, L., et al. (2020). Prevalence and predictors of PTSS during COVID-19 outbreak in China hardest-hit areas: Gender differences matter. Psychiatry Research, 287, 112921.

Lovibond, P. F. (2014). Depression Anxiety and Stress Scales (DASS). 2020, from https://www2.psy.unsw.edu.au/dass/

Mæhlisen, M. H., Pasgaard, A. A., Mortensen, R. N., VardinghusNielsen, H., Torp-Pedersen, C., \& Bøggild, H. (2018). Perceived stress as a risk factor of unemployment: A register-based cohort study. BMC Public Health, 18(1), 728.

Martin, Y. H. (2020). How do SARS and MERS compare with COVID19? Medical News Today. Retrieved April 10, 2020, from https ://www.medicalnewstoday.com/articles/how-do-sars-and-merscompare-with-covid-19. 
Martín Monzón, I. (2007). Estrés académico en estudiantes universitarios. Apuntes de Psicología, ISSN 0213-3334, Vol. 25, $N^{o} .1$, 2007, pags. 87-99, 25.

Matthews, T., Danese, A., Wertz, J., Odgers, C. L., Ambler, A., Moffitt, T. E., et al. (2016). Social isolation, loneliness and depression in young adulthood: A behavioural genetic analysis. Social Psychiatry and Psychiatric Epidemiology, 51(3), 339-348.

Mogilski, J. K., Reeve, S. D., Nicolas, S. C. A., Donaldson, S. H., Mitchell, V. E., \& Welling, L. L. M. (2019). Jealousy, Consent, and Compersion Within Monogamous and Consensually NonMonogamous Romantic Relationships. Archives of Sexual Behavior, 48(6), 1811-1828.

Nurmela, K., \& Mattila, A. (2018). Identification of Depression and Screening for Work Disabilities among Long-Term Unemployed People. 15(5).

Oei, T. P. S., Sawang, S., Goh, Y. W., \& Mukhtar, F. (2013). Using the Depression Anxiety Stress Scale 21 (DASS-21) across cultures. International Journal of Psychology, 48(6), 1018-1029.

Onrust, S. A., \& Cuijpers, P. (2006). Mood and anxiety disorders in widowhood: A systematic review. Aging Ment Health, 10(4), 327-334.

Organization, W. H. (2020). Coronavirus disease 2019. World Health Organization. Retrieved May 24, 2020, from https://www.who.int/ emergencies/diseases/novel-coronavirus-2019.

Osman, A., Wong, J. L., Bagge, C. L., Freedenthal, S., Gutierrez, P. M., \& Lozano, G. (2012). The Depression Anxiety Stress Scales-21 (DASS-21): Further Examination of Dimensions, Scale Reliability, and Correlates. Journal of Clinical Psychology, 68(12), $1322-1338$.

Ozamiz-Etxebarria, N., \& Dosil-Santamaria, M. (2020). Stress, anxiety, and depression levels in the initial stage of the COVID-19 outbreak in a population sample in the northern Spain. 36(4), e00054020.

Ozamiz-Etxebarria, N., Dosil-Santamaria, M., Picaza-Gorrochategui, M., \& Idoiaga-Mondragon, N. (2020). Niveles de estrés, ansiedad y depresión en la primera fase del brote del COVID-19 en una muestra recogida en el norte de España. Cadernos de Saúde Pública, 36.

Özdin, S., \& Bayrak Özdin, Ş. (2020). Levels and predictors of anxiety, depression and health anxiety during COVID-19 pandemic in Turkish society: The importance of gender. International Journal of Social Psychiatry, 0020764020927051.

Özdin, S., \& Bayrak Özdin, Ş. (2020). Levels and predictors of anxiety, depression and health anxiety during COVID-19 pandemic in Turkish society: The importance of gender. Int J Soc Psychiatry, 20764020927051.
Pappa, S., Ntella, V., Giannakas, T., Giannakoulis, V. G., Papoutsi, E., \& Katsaounou, P. (2020). Prevalence of depression, anxiety, and insomnia among healthcare workers during the COVID-19 pandemic: A systematic review and meta-analysis. Brain Behav Immun.

Pietrucha, J. (2018). Country-specific determinants of world university rankings. Scientometrics, 114(3), 1129-1139.

Prevention, C. F. D. C. A. (2017). Quarantine and isolation, 2020. Retrieved from https://www.cdc.gov/quarantine/index.html.

Sareen, J., Erickson, J., Medved, M. I., Asmundson, G. J. G., Enns, M. W., Stein, M., et al. (2013). Risk factors for post-injury mental health problems. Depression and Anxiety, 30(4), 321-327.

Shaw, T., Campbell, M. A., Runions, K. C., \& Zubrick, S. R. (2017). Properties of the DASS-21 in an Australian Community Adolescent Population. Journal of Clinical Psychology, 73(7), 879-892.

Shiel, W. C. (2018). Medical definition of stress. MedicineNet., 2020. Retrieved from https://www.medicinenet.com/script/main/art. asp? articlekey $=20104$.

Times., T. N. Y. (2020). Coronavirus Live Updates: W.H.O. Declares Pandemic as Number of Infected Countries Grows. . The New York Times. Retrieved from https://www.nytimes.com/2020/03/11/ world/coronavirus-news.html\#link-682e5b06.

Wang, C., Horby, P. W., Hayden, F. G., \& Gao, G. F. (2020). A novel coronavirus outbreak of global health concern. Lancet, 395(10223), 470-473.

Wang, C., Pan, R., Wan, X., Tan, Y., Xu, L., Ho, C. S., et al. (2020). Immediate psychological responses and associated factors during the initial stage of the 2019 coronavirus disease (COVID-19) epidemic among the general population in China. International Journal of Environmental Research and Public Health, 17(5), 1729.

Wang, G., Hu, M., Xiao, S. Y., \& Zhou, L. (2017). Loneliness and depression among rural empty-nest elderly adults in Liuyang, China: A cross-sectional study. British Medical Journal Open, 7(10), e016091.

Xiang, Y.-T., Yang, Y., Li, W., Zhang, L., Zhang, Q., Cheung, T., et al. (2020). Timely mental health care for the 2019 novel coronavirus outbreak is urgently needed. The Lancet Psychiatry, 7(3), $228-229$.

Publisher's Note Springer Nature remains neutral with regard to jurisdictional claims in published maps and institutional affiliations. 